\title{
Puberty spectrum in neurofibromatosis - \\ case reports
}

\section{Corina Chirita1 ${ }^{1}$ Camelia Procopiuc ${ }^{2}$, Iuliana Gherlan², Andra Caragheorgheopol², Monica Dragomir ${ }^{3}$, Diana Barca ${ }^{4}$, Cristina Dumitrescu ${ }^{2}$}

1 - Medicover SRL, Bucharest Romania; 2 - National Institute of Endocrinology 'C.I. Parhon', Bucharest, Romania; 3 - Institute of Oncology 'Prof Dr Alex Treistoreanu', Bucharest, Romania; 4 - Clinical Hospital of psychiatry "Prof. dr. A. Obregia, Bucharest, Romania

Neurofibromatosis 1 is a rare autosomal dominant disease determined by mutations in the RAS-MAPK pathway, frequently in the neurofibromin gene (NF1) on chromosome $17 q 11$.

The NF1 protein, neurofibromin, is involved in control of cellular growth and differentiation through the interaction of its GAP related domain with p21ras and tubulin. In the presence of a mutation, Ras is uncontrolled leading to rapid cell proliferation and tumor formation.

Neurofibromatosis 1 phenotype can be more or less severe, including a form that associates the stigma of Noonan Syndrome. It can cause precocious or delayed puberty.

\section{Case 1}

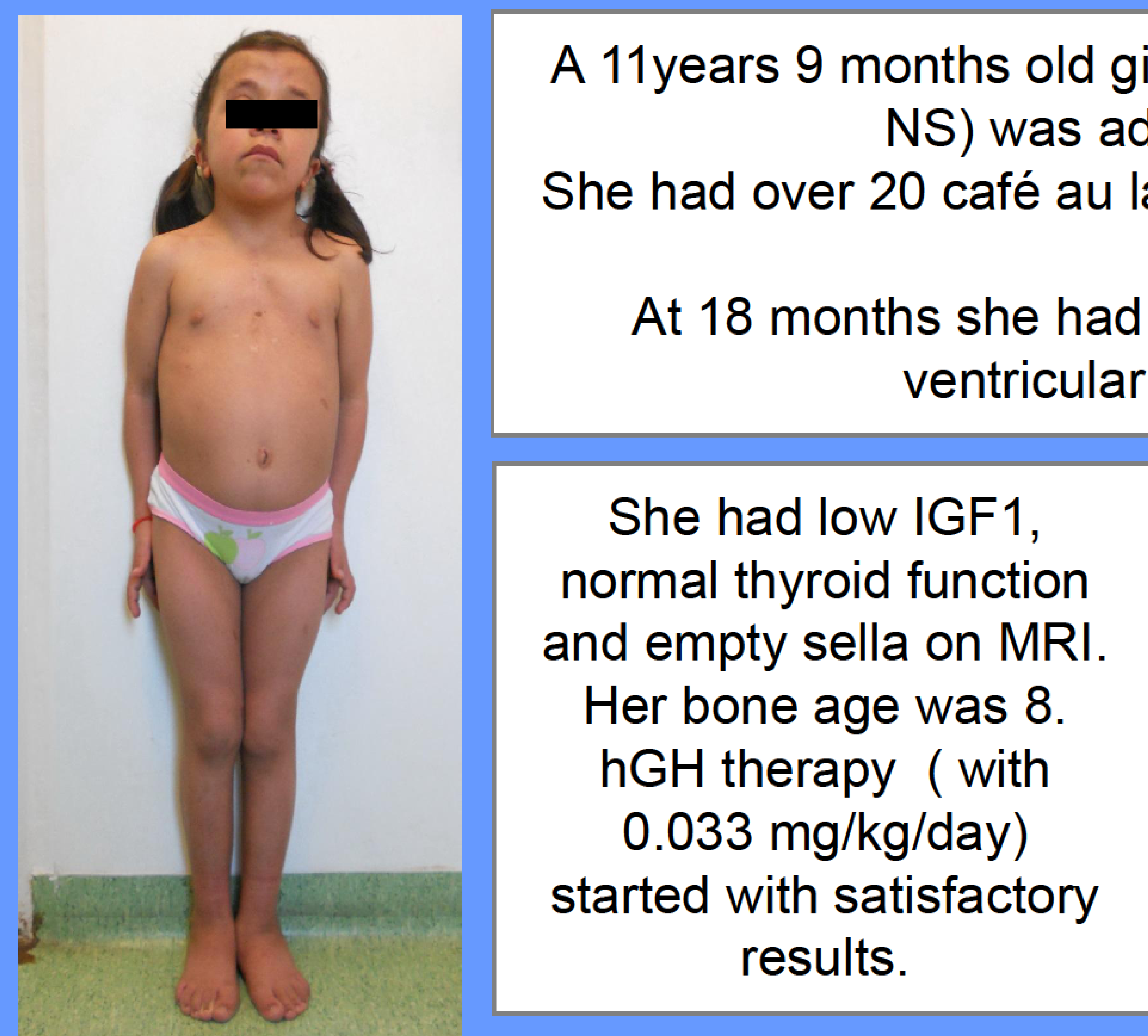

11 years 9 months
After 2 years, at a bone age of 13 she showed no signs of puberty.

A triptorelinum test was negative (basal LH -0.10 $\mathrm{mIU} / \mathrm{mL}$; after triptorelinum

LH -4.29 [cut off 6]). She was diagnosed with delayed puberty and estrogen was started with good results.

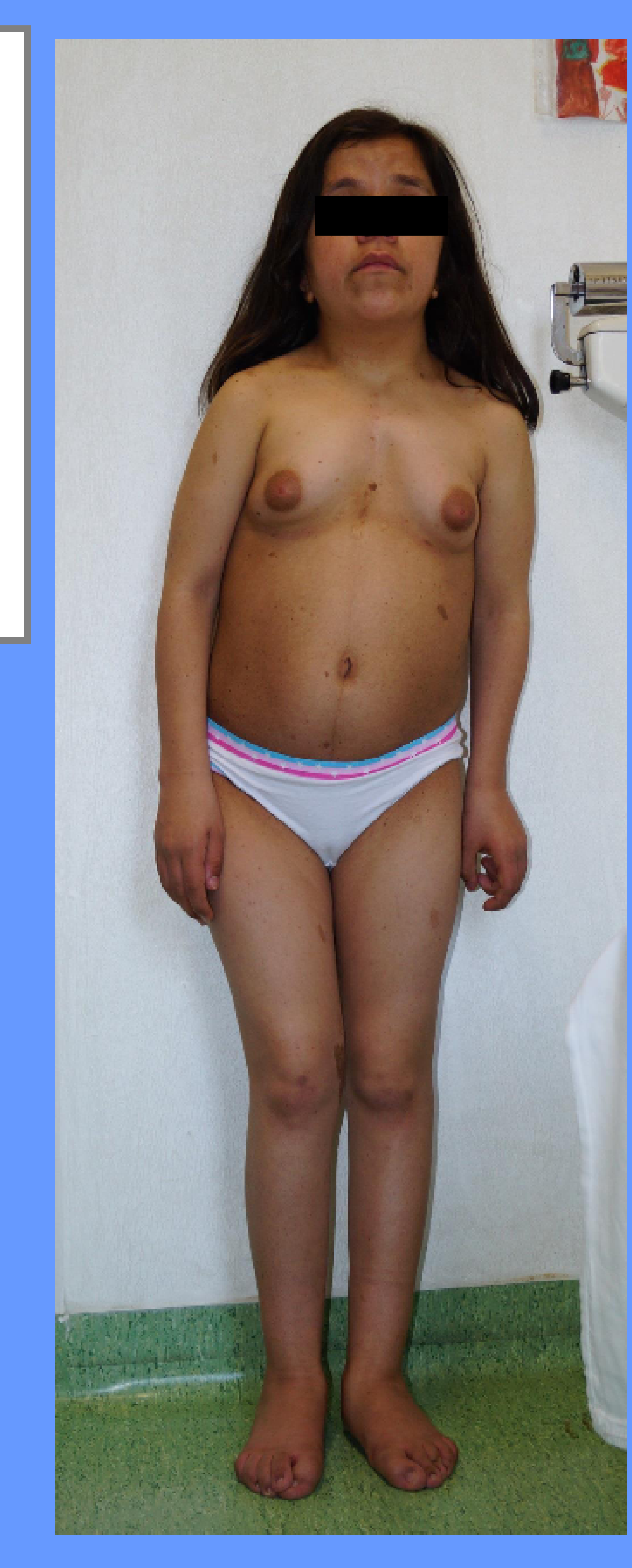

14 years 5 months

\section{Case 2:}

A 5 years old boy was admitted for pubertal evaluation. The clinical exam showed a tall child (+2.55 SDs) with over 10 large café au lait spots and subcutaneous neurofibromas. He was G4 P2 with a $25 \mathrm{ml}$ total testicular volume. A triptorelinum test confirmed central precocious puberty (basal $\mathrm{LH}-2.85 \mathrm{mlU} / \mathrm{mL}$, after triptorelinum $21.89 \mathrm{mIU} / \mathrm{mL}$ ). Bone age was 10 . The cerebral MRI showed multiple neurofibromas and a hamartoma in the third ventricle. He was diagnosed with NF1 and central precocious puberty. Treatment with triptorelinum was started.

At 7 years he presented a seizure and a MRI showed an infiltrative tumor in the right thalamus.

The biopsy showed a pilocytic astrocytoma. Radiotherapy and chemotherapy were started and continued for 18 months with monthly iv treatment. The evolution was favorable and a MRI after the completion of treatment showed no residual tumor

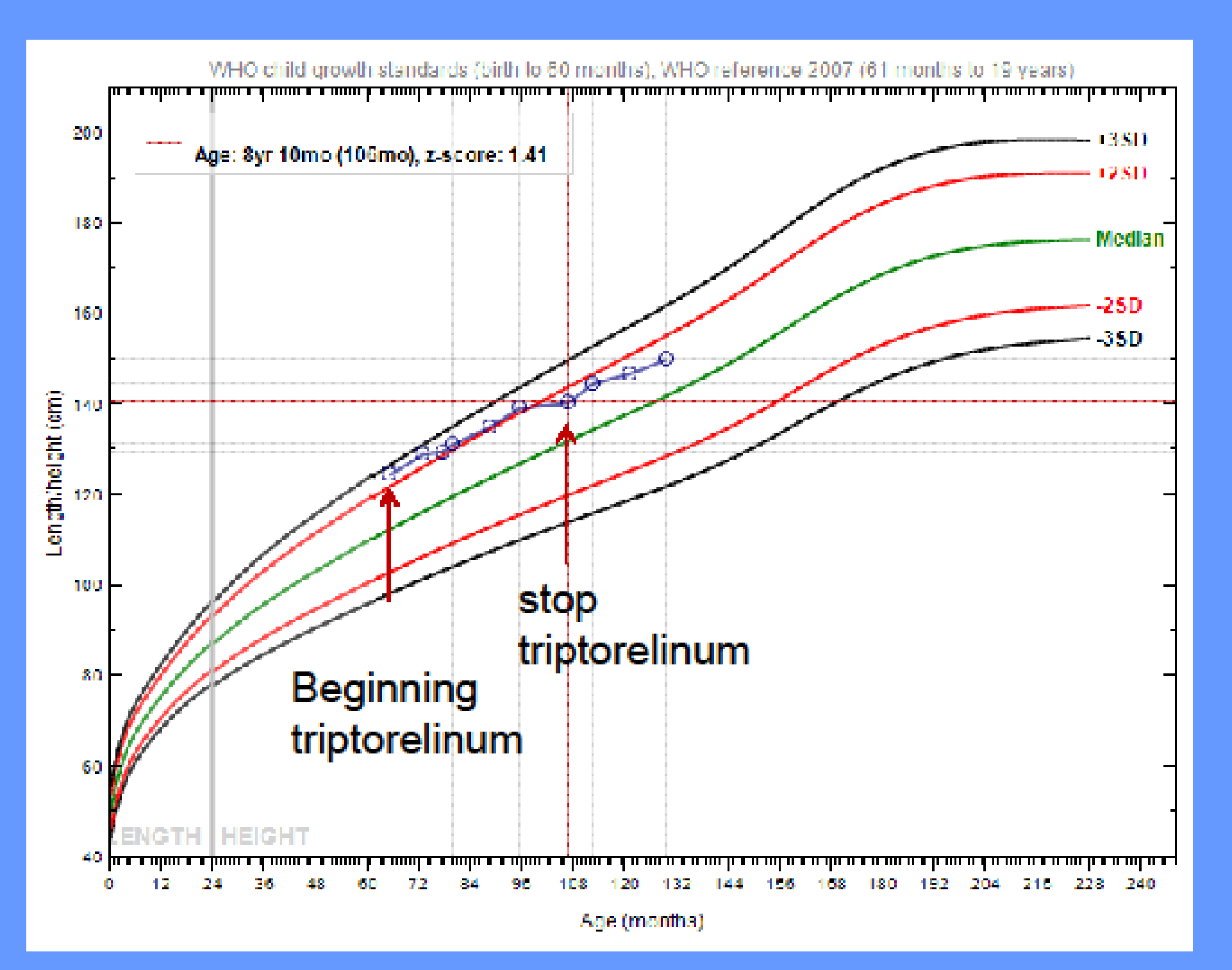

At the age of 9.6 years treatment with triptorelinum was stopped and puberty resumed. He was 1.2 DSD with a bone age of 13

\section{Conclusions:}

NF1 can cause all types of pubertal abnormalities and patients should be monitored closely. NF1 patients have an increased risk for tumor formation due to hyperactivation of the proto-oncogene RAS, an increased incidence of diencephalic syndrome, GH deficiency or GH hypersecretion, pheocromocytoma. Monitoring should be long term, because other complications of the disease can become apparent with time 